\title{
A Gold Electrode Modified with Self-Assembled Diethylene- triaminepentaacetic Acid via Charge-based Discrimination
}

\author{
Jianping LI, ${ }^{\dagger}$ Rong LIU, Jianguo Yu, and Fuyang Jiang \\ College of Chemistry and Bioengineering, Guilin University of Technology, 541004 Guilin, China
}

\begin{abstract}
A gold electrode modified with diethylenetriaminepentaacetic acid (DTPA) has been fabricated to selectively detect dopamine (DA). The influences of experimental parameters were investigated and optimized. The anodic peak current is proportional to the concentration of DA in the range of $1.0 \times 10^{-7}-6.0 \times 10^{-3} \mathrm{~mol} \mathrm{~L}^{-1}$ with a detection limit of $3.0 \times 10^{-8}$ $\mathrm{mol} \mathrm{L}^{-1}(S / N=3)$. DA contents in the serum samples were determined; coexisting ascorbic acid (AA), uric acid (UA) and other oxidizable compounds did not cause interference to the determination. The response of AA and UA during the determination of DA could be suppressed due to the distinct charge discrimination between DA cations and the negative DTPA self-assembled layer in $\mathrm{pH} 7.4$ phosphate-buffered solutions (PBS). The selectivity has been improved significantly; the response time, reproducibility and lifetime of the modified electrode are discussed.
\end{abstract}

(Received March 26, 2009; Accepted May 26, 2009; Published November 10, 2009)

\section{Introduction}

Since its discovery in the 1950s, dopamine (3,4-dihydroxyphenyl ethylamine, DA) has evoked intensive research interest to neuroscientists and chemists. ${ }^{1-4}$ DA is an important neurotransmitter and has been related to various kinds of illnesses, such as Parkinson's disease, senile dementia, Huntington's disease, motivation habits and the regulation of motor function. ${ }^{5-7}$ Hence, the determination of the concentration of this neurotransmitter is very important. Many methods have been developed for determination of DA. ${ }^{8,9}$ Among them, the electrochemical measurements have been investigated extensively due to their excellent properties of low cost and high sensitivity. Furthermore, the most important advantage over other methods is that they can be used to determine DA in living organism. ${ }^{10}$ Various electrodes were used to detect DA: these include diamond electrode, ${ }^{11}$ glassy carbon electrode, ${ }^{12}$ platinum electrode $^{5}$ and gold electrode. However, the major problem of electrochemical detection of DA is the coexistence of interfering compounds, such as ascorbic acid (AA) and uric acid (UA), since AA, UA and DA can be oxidized at a near potential, which leads to the overlap of voltammetric responses. As a result, it is difficult to selectively determine DA directly, and considerable efforts have been devoted to resolving this problem.

One successful approach to improve the selectivity is the use of modified electrodes. A number of modification species, including ion-exchange membranes, ${ }^{13,14}$ ionic liquid gel membrane, ${ }^{15}$ polymer film, ${ }^{12,16-18}$ self assembled membranes ${ }^{19}$ and gold nanoparticles ${ }^{20,21}$ have been employed to improve the selectivity against AA or UA. Ion-exchange membranes, typically Nafion, have been indicated to be capable of preventing the interference from AA and UA. But the disadvantage of Nafion is that the preconcentration process before determination will result in poor reproducibility and non-uniform thickness. ${ }^{22}$ In addition, an electrode coated with Nafion usually suffers from slow response due to a smaller diffusion coefficient value in the film; ${ }^{23}$ an additional disadvantage of Nafion is its high price. Self-assembled membrane-modified electrodes have attracted great attention because of the homogeneous membrane and good electrochemical characters. Self-assembled membranes with cheapness in price, simpleness in fabrication and good selectivity toward DA continue to attract considerable attentions.

Diethylenetriaminepentaacetic acid (DTPA) is an organic compound consisting of a diethylenetriamine backbone modified with five carboxymethyl groups $\left(\mathrm{p} K_{\mathrm{a}} 1.9,2.9,4.4,8.7,10.5\right) .^{24}$ DTPA was widely used for complexation of lanthanide and actinide ions. The complexation characteristics of DTPA are well-known and it has been investigated extensively from various points of view, such as detection of $\mathrm{Cr}^{25}$ However, to the best of our knowledge, there is no report concerning the utilization of its negatively electrostatic interaction to provide a degree of charge-based discrimination for DA over anions.

In the present work, a highly selective electrode for the monitoring of DA was constructed; the monitoring was based on its adsorption and electrostatic interactions for attracting DA while repelling AA and UA. The main consideration of this method is to account for the different forms of DA and AA at the physiological $\mathrm{pH}$ of 7.4. AA exists in the negative charge form $\left(\mathrm{p} K_{\mathrm{a}}=4.1\right)$, while DA is in the positive charge form $\left(\mathrm{p} K_{\mathrm{a}}\right.$ $=8.87) \cdot{ }^{26,27}$ Owing to the capability of charge discrimination, the electrode modified with DTPA, which acts as a cation exchanger, will exclude the anionic AA and sense DA selectively. This electrode enjoys the advantage of simple preparation and surface regeneration by simple polishing. The modified electrode offered the benefit of minimizing interferences of AA and UA during the detection of DA in the serum samples.

† To whom correspondence should be addressed.

E-mail: likianping@263.net 

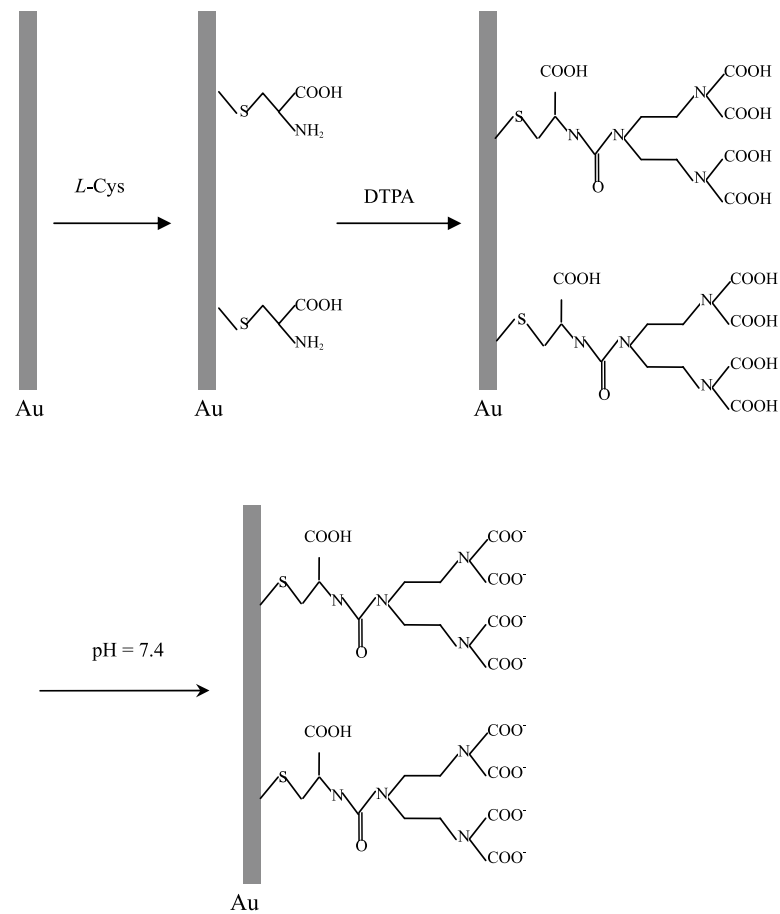

Scheme 1 The assembly process of DTPA-modified electrode.

\section{Experimental}

\section{Apparatus and chemicals}

A CHI660B electrochemistry workstation (Chenhua Instrument Co., Shanghai, China) was used to perform electrochemical detection; a classical three-electrode system was adopted. The DTPA-modified Au electrode $(\phi=0.2 \mathrm{~mm}$ in diameter) acted as the work electrode, a platinum electrode as the counter electrode and an $\mathrm{Ag} / \mathrm{AgCl}$ as the reference electrode. A pHS-2C precision $\mathrm{pH}$ meter (Leici Devices Factory of Shanghai, China) equipped with a combination $\mathrm{pH}$ electrode was used for $\mathrm{pH}$ determination.

Dopamine hydrochloride (DA), uric acid (UA) and human serum albumin (HSA) was purchased from Sigma Company; 1-ethyl-3-(3-dimethylaminopropyl)carbodiimide (EDC) and $\mathrm{N}$-hydroxysulfosuccinimide (Sulfo-NHS) were obtained from Shanghai Convachem Co., Ltd.; diethylenetriaminepentaacetic acid (DTPA) and $l$-cysteine ( $l$-Cys) were purchased from Sinopharn Chemical Reagent Co., Ltd. Ascorbic acid (AA) was purchased form Xilong Chemical Reagent Co., Ltd., Guangzhou. Blood serum was provided by the Hospital of Guilin University of Technology. The phosphate buffer solution was prepared by $\mathrm{Na}_{2} \mathrm{HPO}_{4} \cdot 12 \mathrm{H}_{2} \mathrm{O}$ and $\mathrm{NaH}_{2} \mathrm{PO}_{4} \cdot 2 \mathrm{H}_{2} \mathrm{O}$. All chemicals were analytical grade. Distilled water was used to prepare the solutions and to wash apparatus in experiments.

Electrochemical impedance spectrum (EIS) measurements were carried out in a background solution of $10 \mathrm{mmol} \mathrm{L}^{-1}$ $\mathrm{K}_{3} \mathrm{Fe}(\mathrm{CN})_{6}-\mathrm{K}_{4} \mathrm{Fe}(\mathrm{CN})_{6}$ phosphate buffer $(\mathrm{pH} \mathrm{7.4)}$. The alternating voltage was $5.0 \mathrm{mV}$ and the frequency range was from 0.1 to $100 \mathrm{kHz}$.

\section{Preparation of DTPA/Cys/Au electrode}

The preparation of a modified electrode involves two major steps. The first step is the construction of a $l$-Cys modified electrode. For this purpose, the bare gold electrode was

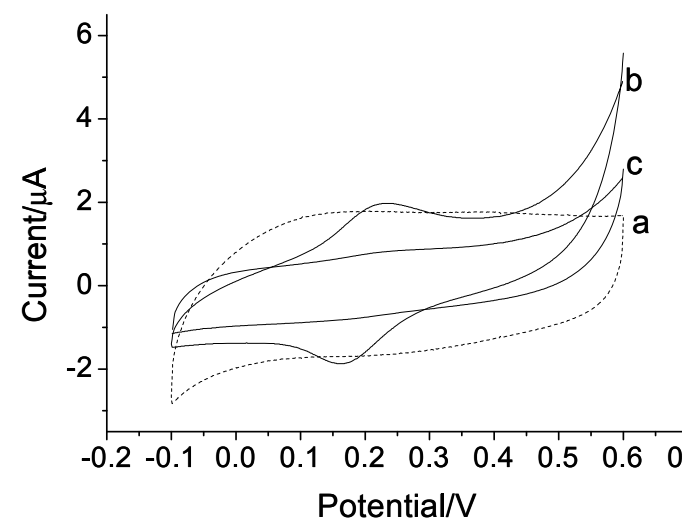

Fig. 1 The cyclic voltammograms of modified electrode in PBS ( $\mathrm{pH}$ 6.0): $\mathrm{a}, \mathrm{Au} ; \mathrm{b}, \mathrm{Cys} / \mathrm{Au} ; \mathrm{c}, \mathrm{DTPA} / \mathrm{Cys} / \mathrm{Au}$.

immersed into a solution of $10 \mathrm{mmol} \mathrm{L}^{-1} l$-Cys in $0.1 \mathrm{~mol} \mathrm{~L}^{-1}$ $\mathrm{HCl}$ for $6 \mathrm{~h}^{28}$ Before modification of the $l$-Cys, the bare gold electrode was polished with $0.05 \mu \mathrm{m} \mathrm{Al}_{2} \mathrm{O}_{3}$ powder, then rinsed ultrasonically with water and absolute ethanol for $3 \mathrm{~min} .{ }^{29}$ Finally, the $\mathrm{Au}$ electrode was electrochemically cleaned by cycling the potential between 1.6 and $-0.4 \mathrm{~V}$ (vs. $\mathrm{Ag} / \mathrm{AgCl}$ ) in $0.5 \mathrm{~mol} \mathrm{~L}^{-1} \mathrm{H}_{2} \mathrm{SO}_{4}$ until a stable voltammogram was obtained. ${ }^{30}$

The second step involves modifying with DTPA. The $l$-Cys modified electrode was immersed in a solution containing $0.05 \mathrm{~mol} \mathrm{~L}^{-1}$ DTPA, $0.02 \mathrm{~mol} \mathrm{~L}^{-1}$ EDC and $0.04 \mathrm{~mol} \mathrm{~L}^{-1} \mathrm{NHS}$ for about $5 \mathrm{~h}^{31}$ to construct the DTPA/Cys/Au electrode, and then the electrode was washed by distilled water. The fabrication of the modified electrode involves two major steps, which are shown in the schematic illustration (Scheme 1).

\section{Procedure}

The electrochemical experiments were carried out in an electrochemical cell holding supporting electrolyte containing $5 \times 10^{-5} \mathrm{~mol} \mathrm{~L}^{-1}$ of DA in $0.2 \mathrm{~mol} \mathrm{~L}^{-1}$ PBS (pH 7.4). Amperometric experiments were carried out at a detection potential of $0.18 \mathrm{~V}$. All experiments were carried out at the room temperature $\left(26 \pm 1^{\circ} \mathrm{C}\right)$.

\section{Results and Discussion}

\section{Characterization of the modified electrode}

The cyclic voltammograms (CVs) and the EIS give the information on the changes of the electrode surface during the modification process.

Curve a in Fig. 1 shows the CVs of the bare Au electrode, there was no voltammetric response on the Au electrode in PBS. Curve $\mathrm{b}$ presents the anodic and cathodic waves of the $l$-Cys modified gold electrode at 0.231 and $0.162 \mathrm{~V}$, respectively. However, both the reductive and oxidative waves disappeared on the DTPA/Cys/Au electrode (curve c). It could be concluded that a nonconductive layer of DTPA has been formed on the Au electrode surface and the layer inhibits electron transfer; thus, no redox reactions are observed.

EIS is a powerful tool for studying the interface characterizations of modified electrodes; it gives the value of electron transfer resistance $\left(R_{\mathrm{et}}\right)$ according to the dielectric and insulating features at the electrode/electrolyte interface. Figure 2 displays the Nyquist plots of the impedance spectroscopy of the electrodes. As shown in Fig. 2, an almost 


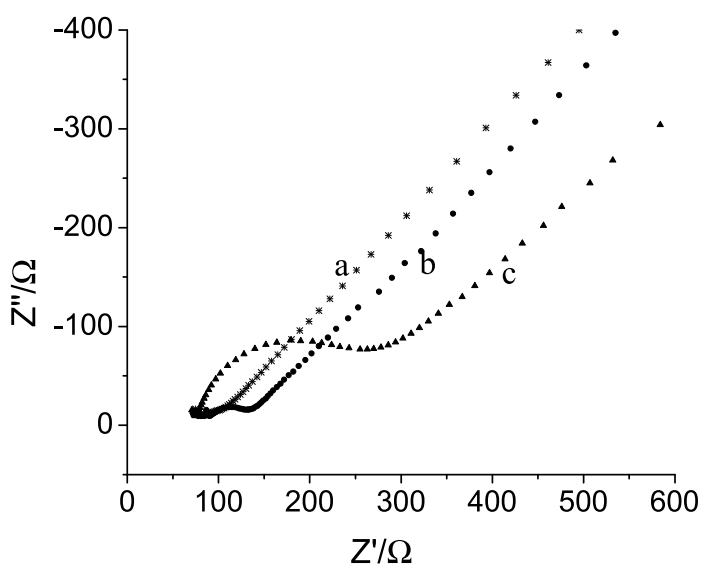

Fig. 2 Nyquist diagram $\left(Z^{\prime \prime} v s . Z^{\prime}\right)$ of the modified electrode: $a, A u$; b, Cys/Au; c, DTPA/Cys/Au.

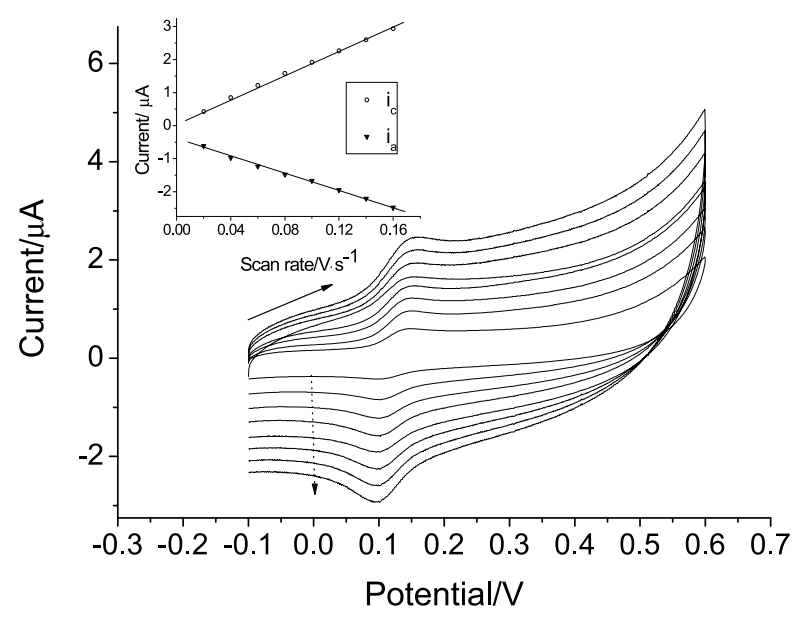

Fig. 3 Cyclic voltammograms of DTPA/Cys/Au electrode in $5 \times$

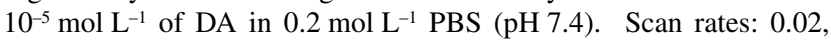
$0.04,0.06,0.08,0.1,0.12,0.14,0.16 \mathrm{~V} \mathrm{~s}^{-1}$. Inset figure is the plots of cathodic and anodic peak currents $v s$. scan rates.

straight line could be observed for the bare Au electrode (curve a); this result implied low transfer resistance to the redox probe dissolved in the electrolyte solution. Curve $b$ is very close to that of the bare Au electrode. After DTPA was linked on the electrode surface which was modified by $l$-Cys, the diameter of the semicircle increased, showing that the modified film obstructed the electron transfer of the electrochemical transfer tunnel. This may be attributed to the weak conductivity of the DTPA-Cys layer.

Electrochemical behaviors of DA at the DTPA/Cys/Au electrode A well-defined redox wave was clearly observed in the solution of PBS ( $\mathrm{pH} 7.4$ ) containing $5 \times 10^{-5} \mathrm{~mol} \mathrm{~L}^{-1} \mathrm{DA}$ at DTPA/Cys/Au electrode at the scan rate of $100 \mathrm{mV} \mathrm{s}^{-1}$ (Fig. 3); the anodic and cathodic peak currents were 1.67 and $-1.99 \mu \mathrm{A}$, respectively.

Figure 3 indicates the effects of scan rates $\left(0.02-0.16 \mathrm{~V} \mathrm{~s}^{-1}\right)$ on the peak currents of DA. The anodic and cathodic peak currents of the modified electrode in the DA solution increased linearly with the increasing scan rates (Fig. 3 insert). The linearity of the plots was very reasonable, with correlation

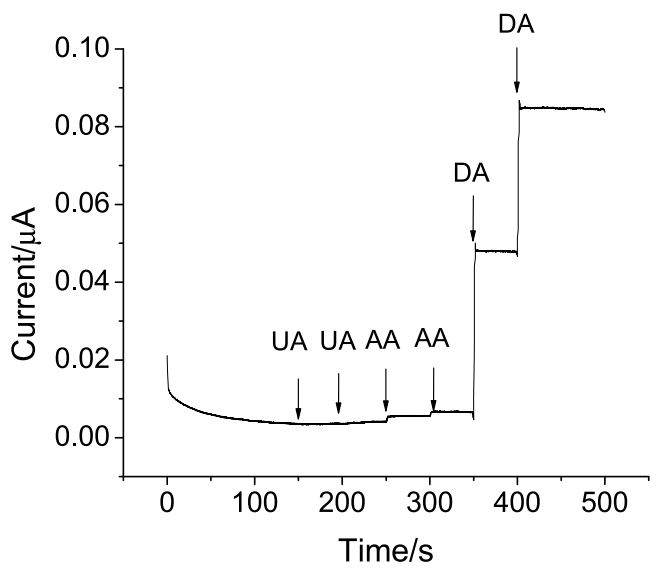

Fig. 4 Amperometric responses of modified electrode held at $0.18 \mathrm{~V}$ in $0.2 \mathrm{~mol} \mathrm{~L}^{-1} \mathrm{PBS}$ under rotating for successive addition of $5.0 \times$ $10^{-5} \mathrm{~mol} \mathrm{~L}^{-1} \mathrm{UA}, 5.0 \times 10^{-5} \mathrm{~mol} \mathrm{~L}^{-1} \mathrm{AA}$ and $5.0 \times 10^{-6} \mathrm{~mol} \mathrm{~L}^{-1} \mathrm{DA}$.

coefficients of 0.9982 on the anodic currents and 0.9988 on the cathodic currents; such values suggest that the reaction of DA at the DTPA/Cys/Au modified electrode is a typical adsorptioncontrolled process.

The effect of the solution $\mathrm{pH}$ values on the response of DA was studied in the range of $5.6-8.4$. It was evident that the peak potential shifted to the negative direction with the increase of $\mathrm{pH}$ values. The relationship between $E_{\mathrm{pa}}$ and $\mathrm{pH}$ was calculated as $E_{\mathrm{pa}}=811.03-87.2 \mathrm{pH}(r=0.99847)$. The redox peak currents of DA increased with the increase of solution $\mathrm{pH}$ value until 7.2, and further increase of $\mathrm{pH}$ beyond 7.2 caused the peak currents to decrease gradually. Since the physiological $\mathrm{pH}$ value of body serum is approximately $7.4,{ }^{32}$ the PBS solution at $\mathrm{pH} 7.4$ was chosen for use in all experiments.

\section{The effect of $A A$ and $U A$ on the determination of $D A$}

The effects of common interfering species on the response of the modified electrode were examined. The tolerated ratio of foreign substances in $5 \times 10^{-6} \mathrm{~mol} \mathrm{~L}^{-1} \mathrm{DA}$ was 600 times for $\mathrm{Ca}^{2+}, \mathrm{Mg}^{2+}$ and $\mathrm{Zn}^{2+}$, and 50 times for $\mathrm{Fe}^{3+}$ and $\mathrm{Cr}^{3+}$, respectively. Human serum albumin (HSA) is the most common protein in serum, and its concentration in serum is approximately $35-50$ $\mathrm{mg} \mathrm{mL} \mathrm{m}^{-1}{ }^{33}$ However, the interferences of HSA in serum could be eliminated efficiently by precipitation using trichloroacetic acid. Our experiment shows that $300 \mathrm{mg} \mathrm{mL}^{-1}$ HAS which was treated by $0.5 \mathrm{~mol} \mathrm{~L}^{-1}$ trichloroacetic acid will not cause interference to the $5 \mu \mathrm{mol} \mathrm{L}{ }^{-1}$ DA. Figure 4 shows the effects of interfering species (i.e., AA and UA) held at $0.18 \mathrm{~V}$. The injections of $50 \mu \mathrm{mol} \mathrm{L}-1$ AA and $50 \mu \mathrm{mol} \mathrm{L}^{-1} \mathrm{UA}$ did not cause obvious interference on the current response, while a subsequent injection of $5 \mu \mathrm{mol} \mathrm{L}^{-1} \mathrm{DA}$ caused an immediate change on the oxidation currents. In addition, further experimental results revealed that $50 \mu \mathrm{mol} \mathrm{L}^{-1}$ AA or $50 \mu \mathrm{mol} \mathrm{L}{ }^{-1}$ UA coexisting with $5 \mu \mathrm{mol} \mathrm{L}{ }^{-1}$ DA yield 0.2 and $1.2 \%$ increase in the oxidation currents, respectively, compared with $5 \mu \mathrm{mol} \mathrm{L}{ }^{-1} \mathrm{DA}$ alone. It is evident that the self-assembled membrane-modified electrode has good selectivity. The concentrations of AA and UA in serum are $10^{-7}-10^{-4}$ $\mu \mathrm{mol} \mathrm{L}{ }^{-1}$ and $160-430 \mu \mathrm{mol} \mathrm{L}^{-1}$, respectively. ${ }^{26,34}$ Cordeiro $^{35}$ had given the AA average values of $28.1-60.2 \mu \mathrm{mol} \mathrm{L}^{-1}$ by detecting it for 35 samples. It is obvious that DA in serum samples can be detected directly, free from the interferences of AA and UA. It has been demonstrated that DTPA contains high 


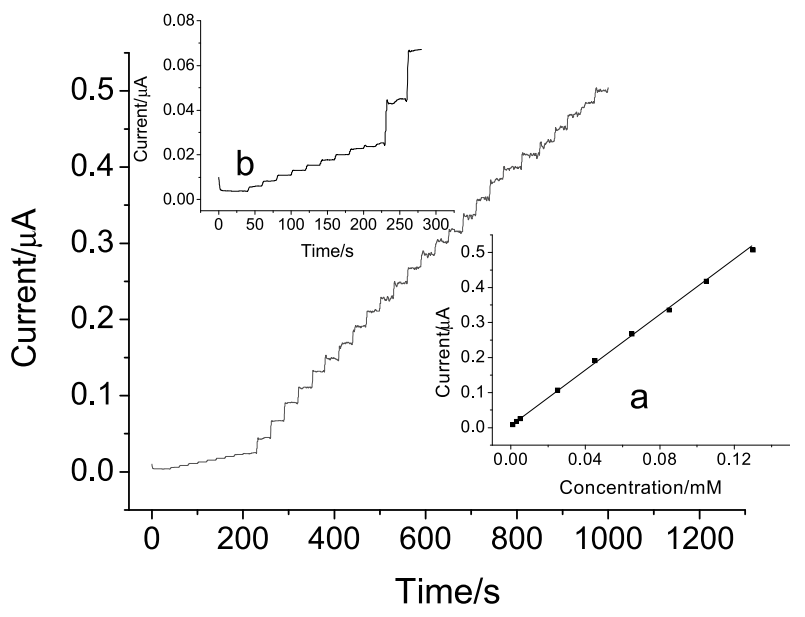

Fig. 5 Typical amperometric response curve obtained by successively adding $0.5 \mu \mathrm{mol} \mathrm{L}^{-1}$ and $5 \mu \mathrm{mol} \mathrm{L}^{-1}$ DA into gently stirred PBS (0.02 mol L-1 $\mathrm{pH} 7.4)$. Inset (a) exhibits the relation between the anodic peak current and the DA concentration; inset (b) is the amplified figure record in the time of $0-260 \mathrm{~s}$.

concentrations of negatively charged functional groups (i.e., -COO) in PBS (pH 7.4); therefore, the negatively electrostatic interaction between anions (e.g., anionic ascorbate) and DTPA provides a degree of charge-based discrimination for DA over anions.

\section{The response of modified electrode to $D A$}

Figure 5 shows the amperometric responses of the DTPA/Cys/Au electrode to the variation of DA concentration. As can be seen, the response time was less than $3 \mathrm{~s}$, which indicated that the response of modified electrode to DA was very rapid. It has been suggested that the wave of DA is mainly controlled by the adsorption of DA on the electrode surface. However, the adsorption balance was reached immediately due to the heavy stirring in amperometric measurements. Under the optimization conditions, the oxidation peak current is proportional to the concentration of DA in the range of $1.0 \times 10^{-7}-6.0 \times 10^{-3} \mathrm{~mol} \mathrm{~L}^{-1}$, with a correlation coefficient of 0.997. The linear regression equation is $\Delta i(\mu \mathrm{A})=-3.8575 C$ $(\mathrm{mmol} \mathrm{L}-1)-0.8750 \times 10^{-2}$. The detection limit $(S / N=3)$ is $3.0 \times 10^{-8} \mathrm{~mol} \mathrm{~L}^{-1}$. The relative standard deviation (RSD) of nine parallel determinations was $2.1 \%$ for $5.0 \times 10^{-5} \mathrm{~mol} \mathrm{~L}^{-1}$ DA; this RSD reveals the excellent repeatability of the DTPA/Cys/Au electrode. The reproducibility of the fabrication procedure under the same conditions was also assessed from different batches; an RSD of $4.8 \%(n=6)$ was obtained for detection of $5.0 \times 10^{-5} \mathrm{~mol} \mathrm{~L}^{-1}$ DA. The stability of the modified electrode was investigated: the peak currents changed very little after storage in air for at least 4 weeks or for cyclic scanning of 350 circles in PBS solution.

\section{Determination of DA in human blood serum}

Under the optimum conditions, the modified electrode was applied to the determination of dopamine by using the amperometric method. The concentrations of DA in human serum were analyzed by the standard addition method. Serum samples were obtained from four volunteers in the Hospital of Guilin University of Technology. In order to avoid interfering of HSA, we added trichloroacetic acid $(20 \% \mathrm{~m} / \mathrm{v})$ to $0.5 \mathrm{~mL}$ serum; centrifugation was carried out for $10 \mathrm{~min}$ at $3000 \mathrm{r} / \mathrm{min}$
Table 1 Results of the determination of DA in human's serum and recovery

\begin{tabular}{cccc}
\hline Sample & $\begin{array}{c}\text { Determined value/ } \\
\mu \mathrm{mol} \mathrm{L}^{-1}\end{array}$ & $\begin{array}{c}\text { Added/ } \\
\mu \mathrm{mol} \mathrm{L}\end{array}$ & Recovery, \% \\
\hline 1 & 4.24 & 0.5 & 100.8 \\
2 & 2.99 & 0.5 & 100.4 \\
3 & 3.58 & 0.5 & 99.6 \\
4 & 1.44 & 0.5 & 100.2 \\
\hline
\end{tabular}

to remove precipitated proteins. Then, $0.5 \mathrm{~mL}$ samples were added into $4.5 \mathrm{~mL}$ of $0.2 \mathrm{~mol} \mathrm{~L}^{-1} \mathrm{PBS}$ solution and DA values were determined. The concentration of DA in the sample of human serum has been calculated by means of an extrapolation method. After $1 \mathrm{~min}, 5.0 \times 10^{-5} \mathrm{~mol} \mathrm{~L}^{-1} \mathrm{DA}$ was added into the solution for testing recoveries. The results are shown in Table 1. The concentrations of DA in the blood serum samples were comparable to the values which are reported. The recoveries were acceptable, showing that the proposed methods could be efficiently used for the determination of DA in serum.

\section{Conclusion}

The DTPA/Cys/Au modified electrode exhibits excellent selectivity for the determination of DA. The success is attributed mostly to the electrostatic interactions between DTPA and DA. The results of $i-t$ show that AA has no interference with DA detection. The electrode is capable of detecting DA in the blood serum. The sensor can be easily fabricated at low cost and shows interesting performance characteristics.

\section{Acknowledgements}

The authors gratefully acknowledge financial support by the National Science Foundation of China (20665003) and the Program to Sponsor Teams for Innovation in the Construction of Talent Highlands in Guangxi Institutions of Higher Learning (GuiJiaoRen [2007]71).

\section{References}

1. S. Jo, H. Jeong, S. R. Bae, and S. Jeon, Microchem. J., 2008, $88,1$.

2. A. Carlsson and B. Waldeck, Acta Physiol. Scandi., 1958, 44, 293.

3. K.-H. Xue, F.-F. Tao, W. Xu, S.-Y. Yin, and J.-M. Liu, J. Electroanal. Chem., 2005, 578, 323.

4. P. Zhang, F.-H. Wu, G.-C. Zhao, and X.-W. Wei, Bioelectrochemistry, 2005, 67, 109.

5. A. Ciszewski and G. Milczarek, Anal. Chem., 1999, 71, 1055.

6. X. Lin, Q. Zhuang, J. Chen, S. Zhang, and Y. Zheng, Sens. Actuators, B, 2007, 125, 240.

7. S. Alwarappan, K. S. A. Butcher, and D. K. Y. Wong, Sens. Actuators, B, 2007, 128, 299.

8. R. K. Shervedani, M. Bagherzadeh, and S. A. Mozaffari, Sens. Actuators, B, 2006, 115, 614.

9. G. Hu, Y. Liu, J. Zhao, S. Cui, Z. Yang, and Y. Zhang, Bioelectrochemistry, 2006, 69, 254.

10. D. L. Robinson, B. J. Venton, M. L. A. V. Heien, and R. M. 
Wightman, Clin. Chem., 2003, 49, 1763.

11. A. Fujishima, T. N. Rao, E. Popa, B. V. Sarada, I. Yagi, and D. A. Tryk, J. Electroanal. Chem., 1999, 473, 179.

12. H. Zhao, Y. Zhang, and Z. Yuan, Analyst, 2001, 126, 358.

13. J. W. Mo and B. Ogorevc, Anal. Chem., 2001, 73, 1196.

14. J. Li, X. Wu, Y. Yu, and S. Le, J. Solid State Electrochem., DOI: $10.1007 / \mathrm{s} 10008-008-0755-4$.

15. Y. Zhao, Y. Gao, D. Zhan, H. Liu, Q. Zhao, Y. Kou, Y. Shao, M. Li, Q. Zhuang, and Z. Zhu, Talanta, 2005, 66, 51.

16. T. Selvaraju and R. Ramaraj, Electrochem. Commun., 2003, $5,667$.

17. H.-S. Wang, T.-H. Li, W.-L. Jia, and H.-Y. Xu, Biosens. Bioelectron., 2006, 22, 664.

18. Y. Zhang, Y. Cai, and S. Su, Anal. Biochem., 2006, 350, 285.

19. G.-Z. Hu, D.-P. Zhang, W.-L. Wu, and Z.-S. Yang, Colloids Surf., B, 2008, 62, 199.

20. F. Patolsky, T. Gabriel, and I. Willner, J. Electroanal. Chem., 1999, 479, 69.

21. C. R. Raj, T. Okajima, and T. Ohsaka, J. Electroanal. Chem., 2003, 543, 127.

22. J. B. Raoof, R. Ojani, and S. Rashid-Nadimi, Electrochim. Acta, 2005, 50, 4694.

23. H. Zhao, Y. Zhang, and Z. Yuan, Electroanalysis, 2002, 14, 1031.
24. E. Marguí, I. Queralt, M. L. Carvalho, and M. Hidalgo, Environ. Pollut., 2007, 145, 179.

25. L. Husáková, A. Bobrowski, J. Šrámková, A. Królicka, and K. Vytřas, Talanta, 2005, 66, 999.

26. M. Kooshki and E. Shams, Anal. Chim. Acta, 2007, 587, 110.

27. J. Zheng and X. Zhou, Bioelectrochemistry, 2007, 70, 408.

28. X. Ma, H. Yang, X. Sun, J. Ji, and Q. Ya, Chin. J. Org. Chem., 2007, 65, 1617.

29. L.-M. Niu, H.-Q. Luo, and N.-B. Li, Microchim. Acta, 2005, $150,87$.

30. Y. Bai, L. Wang, J. Wang, F. Huang, P. Zhao, and Y. Fan, Microchim. Acta, 2007, 156, 321.

31. J. Li, S. Le, Q. Li, and X. Zhang, Electroanalysis, 2009, 21, 831.

32. M. K. Ziglar, Int. J. Trauma Nurs., 2000, 6, 81.

33. J. N. Adkins, S. M. Varnum, K. J. Auberry, R. J. Moore, N. H. Angell, R. D. Smith, D. L. Springer, and J. G. Pounds, Mol. Cell. Protemoics, 2002, 1, 947.

34. Z. Chi, J. Hong, J. Yang, H. Zhang, M. Dai, B. Cui, Y. Zhang, W. Gu, Y. Zhang, Q. Liu, W. Wang, X. Li, and G. Ning, Endocrine, 2007, 32, 122.

35. M. B. C. Cordeiro, É. J. Antonelli, D. F. da Cunha, A. A. J. Júnior, V. R. Júnior, and H. Vannucchi, Nutrition, 2005, 21, 901. 